\title{
God Knows (But does God Believe?) ${ }^{1}$ \\ Dylan Murray, Justin Sytsma, and Jonathan Livengood
}

The standard view in epistemology is that propositional knowledge entails belief. Positive arguments are seldom given for this entailment thesis, however; instead, its truth is typically assumed. Against the entailment thesis, Myers-Schulz and Schwitzgebel (forthcoming) report that a non trivial percentage of people think that there can be propositional knowledge without belief. In this paper, we add further fuel to the fire, presenting the results of four new studies. Based on our results, we argue that the entailment thesis does not deserve the default status that it is typically granted. We conclude by considering the alternative account of knowledge that Myers-Schulz and Schwitzgebel propose to explain their results, arguing that it does not explain ours. In its place we offer a different explanation of both sets of findings - the conviction account, according to which belief, but not knowledge, requires mental assent.

Few claims in philosophy are as widely held as that propositional knowledge entails belief.

Certainly, this entailment thesis is the standard view in contemporary epistemology. ${ }^{2}$ But why? Although some positive arguments for the thesis can be found in the literature, it is not often argued for; instead, it is generally assumed to be true until proven false. In other words, many epistemologists have treated the entailment thesis as having a default status. We argue that the entailment thesis does not deserve this status. Toward that end, we expand on the recent experimental work of Blake Myers-Schulz and Eric Schwitzgebel (forthcoming) by presenting four new cases in which a significant percentage of adult Americans ascribe knowledge to an agent but not the corresponding belief. We do not contend that this shows that the entailment thesis is false; rather, it shows that it cannot simply be assumed to be true.

We proceed as follows: In Section 1, we review the case that has been made for the entailment thesis, and, in Section 2, we discuss Myers-Schulz and Schwitzgebel's challenge to it. In Section 3, we expand on their challenge, reporting the results of four new studies that use cases that are rather different from theirs. In Section 4, we respond to several objections

\footnotetext{
${ }^{1}$ We would like to thank Blake Myers-Schulz, Eric Schwitzgebel, Jacob Beck, and an anonymous referee for their comments on previous versions of this article. We would also like to thank the audiences in Seattle and Savannah.

${ }^{2}$ To our knowledge, Lehrer (1968) was the first to introduce the moniker of the "entailment thesis."
} 
that could be raised against our examples. We conclude, in Section 5, by considering what these results mean for accounts of knowledge and belief, noting that the view put forward by Myers-Schulz and Schwitzgebel (the capacity-tendency account of knowledge) does not explain the results of our new studies. We tentatively suggest that the full set of results is better explained by the hypothesis that there is an assent condition on belief but not knowledge.

\section{The Case for the Entailment Thesis}

Positive arguments are seldom given for the entailment thesis (though see below). Instead, it is typically treated as the default position. ${ }^{3}$ To briefly illustrate, consider Matthias Steup's (2006) Stanford Encyclopedia of Philosophy article on "The Analysis of Knowledge.” He begins by presenting the justified true belief account:

$S$ knows that $p$ iff

i. $p$ is true;

ii. $S$ believes that $p$;

iii. $S$ is justified in believing that $p$.

Steup asserts that (i) is obvious and that it "has not generated any significant degree of discussion." In contrast, he notes that (ii) has generated some discussion: "Although initially it might seem obvious that knowing that $p$ requires believing that $p$, some philosophers have argued that knowledge without belief is indeed possible."

Specifically, Steup briefly considers Colin Radford's (1966) purported counterexample to condition (ii) in which Jean is challenged to a quiz about English history. While Jean sincerely claims not to know any English history and takes himself to be guessing at the answers, he manages to answer all of the questions correctly. For instance, Jean correctly answers that Queen Elizabeth died in 1603. Upon some prodding - "You couldn't just have been guessing, Jean, could you?"- - he responds: "Yes, you know—come to think of

\footnotetext{
${ }^{3}$ Myers-Schulz and Schwitzgebel note several recent textbooks and review articles that treat the entailment thesis in this way, including Audi (1998), Williams (2001), and Feldman (2003).
} 
it - I think I remember I did once have to learn some dates" (3). Radford's intuition about this case is that Jean knew that Queen Elizabeth died in 1603 (he answered correctly based on prior learning) but that he did not believe it (he had forgotten that he had previously learned this fact). That is, Radford takes this example to be a case of propositional knowledge without belief.

Echoing a charge put forward by Keith Lehrer (1968), Steup claims that Radford's counterexample is uncompelling: "Those who think that belief is necessary for knowledge could reply that the example does not qualify as a case of knowledge without belief because it isn’t a case of knowledge to begin with” (§1.1). Specifically, the example is said to fail condition (iii) above: Jean does not know that Queen Elizabeth died in 1603 because he has no justification for believing that this is so. Radford, of course, has the opposite intuition, based on the fact that Jean learned this answer and did not get it right by chance. While Radford accepts that Jean did not know that he knew the answer, he denies that this implies that Jean did not know it.

Importantly, however, Steup does not take this conflict to leave the entailment thesis in any doubt. Instead, he simply denies Radford's intuition and rules that the example is uncompelling. Here, we see the default status of the entailment thesis clearly at work: Absent a compelling counterexample, it is assumed to be true-presumably because it just seems intuitively obvious.

Though rare, positive arguments for the entailment thesis have been given - notably, in two of the most prominent responses to Radford's counterexample: Lehrer (1968) and Armstrong (1969). Each begins by denying that the example is a case of knowledge without belief, but for different reasons: Lehrer denies that it is a case of knowledge; Armstrong contends that it is a case of both knowledge and belief. Interestingly, each author goes beyond his rejection of Radford's counterexample to offer a general argument for the 
entailment thesis, and these might be thought to break the intuitional stalemate seen above. Upon inspection, however, each argument hinges on the same contested intuitions about knowledge and belief at issue in the original scenario.

Lehrer denies that Radford's scenario is a counterexample to the entailment thesis because it fails to be a case of knowledge. He bases this claim on an alternative case in which a man answers a question correctly, but where his doing so really is pure guesswork. As Lehrer notes, however, Radford can readily respond that this example is not analogous to his own: While Jean believes that he is guessing, he is actually remembering a fact that he had previously learned. In response, "rather than pursue further the strategy of meeting counterexamples with counterexamples," Lehrer proposes to "instead offer a general proof that the entailment thesis is true and thereby show that there can be no counterexample to it" (498-497).

We will not rehearse Lehrer's full argument here, but only its central premise: "If, even though a man correctly says that $p$ and knows he has said that $p$, he does not know he correctly says that $p$, then he does not know that p" (497). While Lehrer's argument turns on this premise, it is not one that Radford accepts - his counterexample assumes that Jean knows something despite not knowing that he knows it (he thinks he is only guessing). As such, Radford could respond that in order for a person to know that $p$, it is sufficient that the memory-trace encoding the content that $p$ was laid down by a reliable cognitive process. Lehrer, of course, has famously conflicting intuitions, as illustrated by his Truetemp thought experiment (1990: 163-4). Thus, when Lehrer's positive argument for the entailment thesis is scrutinized, one finds that it hinges on exactly the intuitions that Radford denies. The argument cannot, then, provide an independent means of resolving the intuitional stalemate evinced by Radford's example. 
Armstrong's (1969) response to Radford's counterexample is somewhat different. He tentatively accepts that it is a case of knowledge, but also a case of belief. Armstrong argues for this conclusion by comparing two variations on it:

Case 2: The subject is again asked the same question, and, as it seems to him, "simply guesses" 1603. But in fact he was once taught this date (as he later recollects), and this teaching, and the memory-trace that was produced by the teaching, was causally responsible for his picking this date rather than any other (30).

Case 4: The subject is asked the question and, as it seems to him, "simply guesses" 1603. In fact he had in the past been taught this date. Unfortunately, however, although the teacher said "1603" the subject took it in as "1306". Fortunately, however, the memory-trace degenerated over the course of time, and, although it originally encoded " 1306 " came to encode " 1603 ". It was this degenerate trace that caused the subject to say " 1603 " (32).

Armstrong takes these to be cases of knowledge and belief, respectively. He then argues, based on the similarity of the two cases, that they must involve a common factor. "[A]nd what can that common factor be except that in both cases the subject believes that Elizabeth died in 1603?" (33). In other words, Armstrong takes Radford to have misdescribed his scenario. Despite initial appearances, Case 2 is an example of both knowledge and belief. Armstrong goes on to generalize this challenge, asserting that similar considerations could be brought against any purported counterexample:

The failure of Radford's argument does not by itself mean that the doctrine... must be given up. But I think that against any case which is claimed to be a case of [knowledge without belief] considerations similar to the ones brought against Radford can be brought (33-34).

Leaving aside the haste of its generalization, the argument hinges on Armstrong's critique of Radford's example involving Jean. There are, however, two key problems with this critique. First, even if it is granted that Case 4 is a case of belief, belief is not the only common factor that might explain the similarity between the two cases. In fact, there is a rather obvious alternative: In each case, the subject has a "memory-trace" encoding the same content. But, whether or not the subject in Case 2 believes the content of that memory-trace is another question entirely. Second, it's not clear that Case 4 is a case of belief: As in the original example, the subject in Case 4 takes himself to be guessing that Elizabeth died in 1603, 
which Radford takes to undermine belief. Once again, then, the road leads to a conflict of intuitions - this time concerning belief rather than knowledge.

\section{Myers-Schulz and Schwitzgebel's Challenge}

Some philosophers agree with Radford's (1966) conclusion about his example, but most simply deny that it is, intuitively, a case of knowledge without belief. ${ }^{4}$ And as we have seen, the few positive arguments for the entailment thesis rest on similar intuitions. We seem, then, to be left in something of a predicament: What can be done to break the intuitional stalemate?

Radford himself offers some advice on this score: "ultimately, whether [Jean] 'knows' is a question of what 'know' means, which in turn is very much a matter of when, in what situations, English speakers say or would say that someone knows or does not know" (5). Radford goes on to claim that this is not "simply a matter of appealing to one's intuition and then checking this against the result of some Naessian survey" (5). ${ }^{5}$ We should not, in other words, base an analysis of knowledge simply on surveys of intuitions. We must also consider the reasons for our judgments and weigh them against other relevant considerations. Radford, for instance, claims that Jean remembers that Elizabeth died in 1603, which (taking remembering to entail knowing) gives us reason to judge that Jean knew this.

We agree that the status of the entailment thesis ultimately depends on what English speakers mean by 'knows' and related terms, and we agree that surveys of intuitions are no substitute for investigations of what reasons there are for different positions on that matter. But this is not to say that surveys of intuitions have no role to play in the philosophical dialectic. Quite the contrary. Such studies can provide a valuable inroad to resolving

\footnotetext{
${ }^{4}$ Those who share Radford's intuition include, e.g., Black (1971: 154), Margolis (1973: 7), Mannison (1976: 139), Lewis (1996: 556), and Schope (2002: 53-55). In addition to Lehrer (1968) and Steup (2006), Jones (1966) and Sorensen (1982) maintain that Jean neither knows nor believes that Queen Elizabeth died in 1603. Cohen (1966: 11) sides with Armstrong (1969) in holding that Radford's is an example of both knowledge and belief. ${ }^{5}$ The reference is to proto-experimental philosopher Arne Naess, one of the first to use questionnaires in studying non-philosophers' intuitions about philosophical issues. See, e.g., Naess (1938).
} 
intuitional stalemates by determining whether the non-standard intuition (amongst philosophers) can be written off as idiosyncratic. If we are going to consult intuitions (as those in the debate over the entailment thesis do), then we have reason to survey the intuitions of non-philosophers to ensure that our own are not biased by training or the philosophical positions that we have adopted. And, if we have reason to consult the intuitions of non-philosophers, then we have reason to do so systematically. We have reason, then, to do experimental philosophy.

In this vein, Myers-Schulz and Schwitzgebel (forthcoming) not only present a series of five purported counterexamples to the entailment thesis, including a case based on Radford's, but empirically test the judgments of English speaking non-philosophers concerning those cases. In each of the cases (and significantly so in three of the five), they found that the percentage of participants who judged that an agent knew a proposition was higher than the percentage who judged that the agent believed it. For example, in their Unconfident Examinee case, $87 \%$ of participants answered that Kate knows that Queen Elizabeth died in 1603 , while only $37 \%$ of participants judged that Kate believes that fact. In the Freaked-Out Movie-Watcher, $83 \%$ of participants judged that Jamie knew that only water (rather than aliens, as in a horror film she had just seen) would come out of a faucet, but only $30 \%$ that she believed as much. In the Prejudiced Professor, $63 \%$ judged that Juliet knows that her athletic and non-athletic students are equally academically capable, but only $23 \%$ judged that Juliet believes this. The results of these studies tell against the default status of the entailment thesis.

There are, however, several potential shortcomings of Myers-Schulz and Schwitzgebel's studies. First, each of their studies used a between-subjects design (each participant was asked either whether a given scenario involved knowledge or belief, but not both). One could worry that participants might, as a result, have failed to entertain relevant 
considerations in making their judgments. ${ }^{6}$ Second, each of Myers-Schulz and

Schwitzgebel's examples involves a human agent whose actions fail to correspond with what he/she knows because of some failing (nervousness, absent-mindedness, prejudice, selfdeception). For purposes of building a case against the default status of the entailment thesis, such similarities are potentially problematic: They render it more likely that a critic could dismiss their results wholesale. Indeed, David Rose and Jonathan Schaffer (ms) have raised just such a critique against Myers-Schulz and Schwitzgebel's interpretation of their results.

Rose and Schaffer note several problems with Myers-Schulz and Schwitzgebel's studies, but their primary objection is that each of the scenarios likely elicits responses regarding an occurrent sense of belief rather than a dispositional sense. According to Rose and Schaffer, however, only the former sense (which they articulate in terms of information available to the mind) is relevant to the issue at hand: The entailment thesis holds that knowledge entails dispositional belief, but is silent on the relation between knowledge and occurrent belief. Thus, they argue that in the Unconfident Examinee, Kate both knows and dispositionally believes that Queen Elizabeth died in 1603. Kate has this information stored in her mind — she has a memory-trace of it, as Armstrong puts it—but is blocked from accessing this information normally (her dispositional belief is masked by her nervousness). ${ }^{7}$ Rose and Schaffer suggest that participants in Myers-Schulz and Schwitzgebel's studies only took the Unconfident Examinee and Freaked-Out Movie-Watcher to be cases of knowledge without belief because they either interpreted the questions to be asking about (irrelevant) occurrent belief, or else failed to appreciate the fact that dispositions can be masked. When Rose and Schaffer presented the scenarios to participants in ways designed to clarify the type

\footnotetext{
${ }^{6}$ Rose and Schaffer (ms) have, however, replicated Myers-Schulz and Schwitzgebel's results for the Unconfident Examinee and Freaked-Out Movie-Watcher using a within-subjects design.

${ }^{7}$ See, e.g., Johnston's (1992) example involving a glass encased in packaging. The glass has the disposition of being fragile, but it would not break if struck because the packaging would mask this disposition from being manifested.
} 
of belief purportedly at issue, they found that most took them to be cases of both knowledge and dispositional belief.

\section{New Experiments on the Entailment Thesis}

We are sympathetic with the conclusion that Myers-Schulz and Schwitzgebel draw about the status of the entailment thesis, but our agreement is based partly on intuitions about very different cases. To ensure that our intuitions are not idiosyncratic, we conducted four new empirical studies, the results of which we present in this section. These studies add further fuel to Myers-Schulz and Schwitzgebel's fire, and they also address each of the potential shortcomings of their studies noted above. Thus, three of our four studies utilize a withinsubjects design: We ask each participant both whether the agents in the scenarios know a certain proposition and whether they believe it. Further, the scenarios vary greatly in terms of the types of agents involved (God, a cash register, a dog, and a human), rendering the resultant set of counterexamples less vulnerable to any one objection. In particular, and as we argue in the next section, our examples are not subject to the primary challenge raised by Rose and Schaffer.

\subsection{God}

The basic idea behind our first study is that it seems (to us) that we more readily ascribe knowledge than belief to some kinds of agent. For example, while we readily say that God knows various simple propositions (on the assumption that God exists), we hesitate to say that God believes them. Our first study sought to test this intuition.

For this study we used a between-subjects design, with each participant randomly assigned one of the following two yes/no questions:

Does God know that $2+2=4$ ?

Does God believe that $2+2=4$ ? 
On a second page, participants were then asked whether they believed in God (our concern being that non-believers might answer that God does not know/believe because God does not exist). Responses were collected from 101 participants. ${ }^{8} 93.1 \%$ of the 58 participants receiving the first question answered that God knows, while only $65.9 \%$ of the 44 receiving the second question answered that God believes. This difference was statistically significant. ${ }^{9}$ Restricting to the 87 participants who answered that they believe in God, the difference remains significant: $98.0 \%$ answered that God knows; $73.0 \%$ that God believes. ${ }^{10}$ Results are shown in Figure 1.
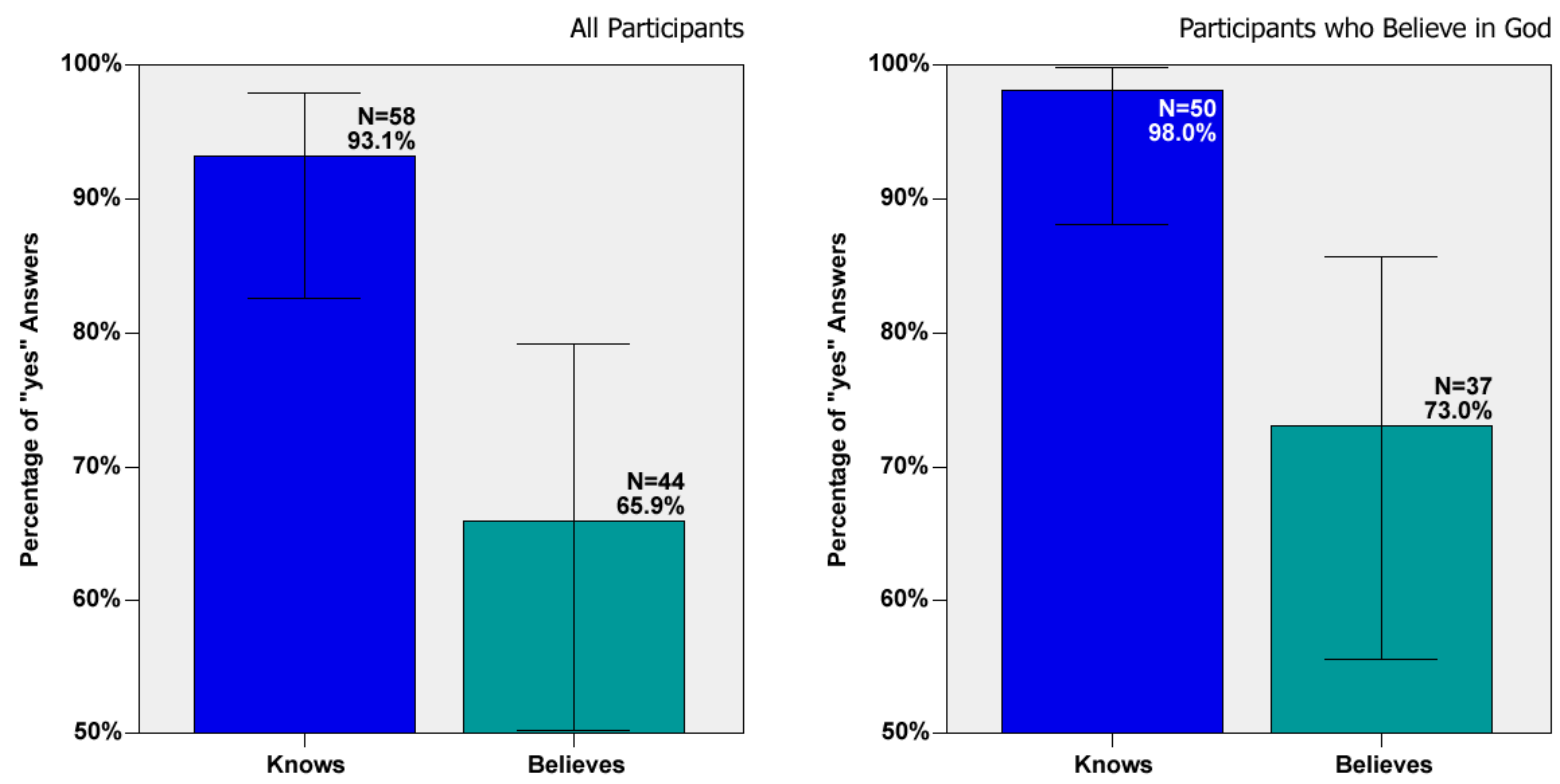

Fig. 1. Results of Study 1, with 95\% Confidence Intervals.

\footnotetext{
${ }^{8}$ In all studies, participants were native English speakers, 18 years of age or older, with at most minimal training in philosophy (excluding philosophy majors and those who have taken graduate-level courses in philosophy). All participants were recruited through the Philosophical Personality website (http://philosophicalpersonality.com).

${ }^{9}$ Two-sample test for equality of proportions with continuity correction, $\chi^{2}=10.48, \mathrm{df}=1, \mathrm{p}=0.0012$.

${ }^{10}$ Two-sample test for equality of proportions with continuity correction, $\chi^{2}=9.89, \mathrm{df}=1, \mathrm{p}=0.0017$.
} 


\subsection{Dog}

In our second study, we asked participants about a rather different type of being-a border collie named Cassie. Participants were given the following short vignette:

Researchers have found that some breeds of dog are surprisingly intelligent. Amongst the most intelligent are border collies. One border collie, Cassie, is even able to solve simple mathematical problems: If you ask her "what is $2+2$," for example, she will bark four times; similarly, if you ask her "what is $4+5$ " she'll bark nine times!

Expecting that many participants would deny that Cassie knows that $2+2=4$, we used a within-subjects design, with each participant being asked two yes/no questions (counterbalanced for order) corresponding to those used in Study 1.

Advocates of the claim that propositional knowledge entails belief will make two predictions about this case: (i) if a participant says that Cassie knows that $2+2=4$, then that participant will say that Cassie believes that $2+2=4$; and, (ii) if a participant says that Cassie does not believe that $2+2=4$, then that participant will say that Cassie does not know that $2+2=4$. Making a liberal estimate for the amount of noise involved in real observations, we think that finding more than $20 \%$ of the relevant participants violating either condition would cast serious doubt on the default status of the entailment thesis.

Responses were collected from 190 participants. Among those who answered that Cassie knows that $2+2=4,52.5 \%$ answered that Cassie does not believe as much, which is a significantly greater percentage than the $20 \%$ noise threshold. ${ }^{11}$ Likewise, among participants who answered that Cassie does not believe that $2+2=4,45.7 \%$ answered that Cassie nonetheless knows. ${ }^{12}$ Results are shown in Figure 2.

\footnotetext{
${ }^{11}$ One-sample test of proportion with continuity correction, $\chi^{2}=64.56, \mathrm{df}=1, \mathrm{p}<.001 ; 95 \% \mathrm{CI}[0.42,0.62]$.

${ }^{12}$ One-sample test of proportion with continuity correction, $\chi^{2}=46.25, \mathrm{df}=1, \mathrm{p}<.001 ; 95 \% \mathrm{CI}[0.36,0.55]$.
} 

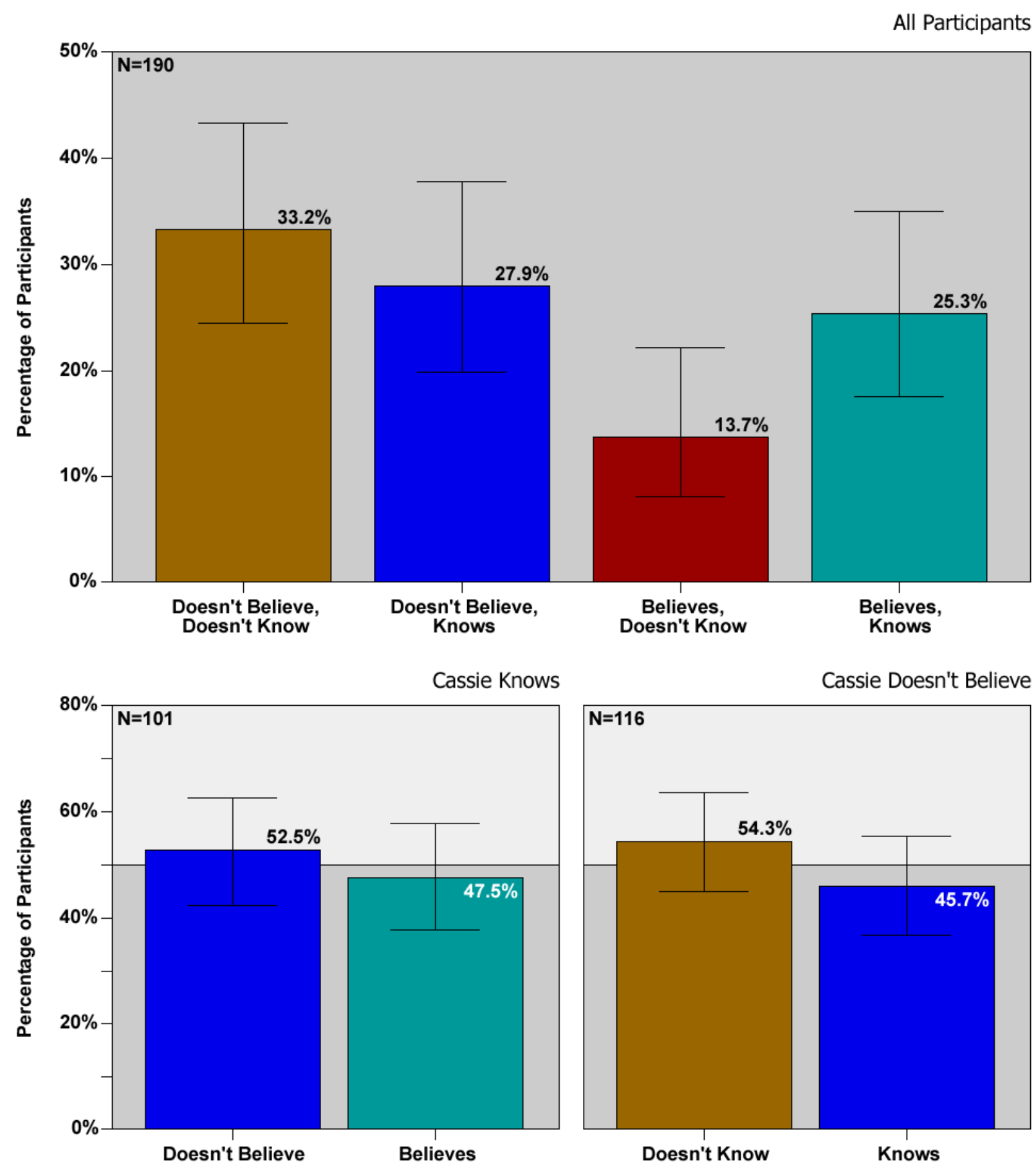

Fig. 2. Results of Study 2, with 95\% Confidence Intervals. All participants above; participants answering that Cassie knows bottom left; participants answering that she doesn't believe bottom right. 


\subsection{Cash Register}

In our third study, we asked participants about an even less complex being than Cassie - a

cash register. Participants were given the following vignette (adapted from Sytsma 2010):

It is an ordinary Saturday morning and Mary is at the supermarket picking up some groceries. When she went to check out there were lines in every lane that had a human cashier; several of the new "self checkout" lanes had no wait, however. In the self checkout lane, there is an item scanner attached to a cash register: You scan your items and when you are done the cash register displays how much you owe and takes your payment (having slots for cash or credit cards).

Mary had never used one of these self checkout lanes before and was a bit nervous about doing so. Nonetheless, she didn't want to wait in line and decided to give it a try. Everything went fairly smoothly. Mary scanned the items in. When she was done she hit total. The cash register then displayed the total amount that Mary owed: $\$ 42.73$. Mary double-checked the amount displayed and found that it was accurate. It took her some time to do this, however, and after a minute the cash register started to beep. When Mary inserted her credit card, the beeping stopped. Mary finished paying with no further trouble. Overall, Mary thought the self checkout lane worked quite well and thought that she would use it again.

Each participant was then given two yes/no questions (counterbalanced for order):

Did the cash register know that Mary's total was $\$ 42.73$ ?

Did the cash register believe that Mary's total was $\$ 42.73$ ?

On a second page, participants were asked whether they had understood the questions literally.

Again, the advocate of the entailment thesis should make two predictions about this case: (i) if a participant says that the cash register knew that Mary's total was $\$ 42.73$, then that participant will say that the cash register believed that Mary's total was $\$ 42.73$; and, (ii) if a participant says that the cash register did not believe, then that participant will say that the cash register did not know. Once again, though, neither prediction was borne out by the data.

Responses were collected from 194 participants. Among those who answered that the cash register knew, 34.9\% answered that it did not believe, which is a significantly greater percentage than the $20 \%$ noise threshold. ${ }^{13}$ Likewise, among those who answered that the cash register did not believe, $81.1 \%$ answered that it knew. ${ }^{14,15}$ Results are shown in Figure 3.

\footnotetext{
${ }^{13}$ One-sample test of proportion with continuity correction, $\chi^{2}=22.89, \mathrm{df}=1, \mathrm{p}<.001 ; 95 \% \mathrm{CI}[0.28,0.43]$.

${ }^{14}$ One-sample test of proportion with continuity correction, $\chi^{2}=168.76, \mathrm{df}=1, \mathrm{p}<.001 ; 95 \% \mathrm{CI}[0.70,0.89]$.
} 

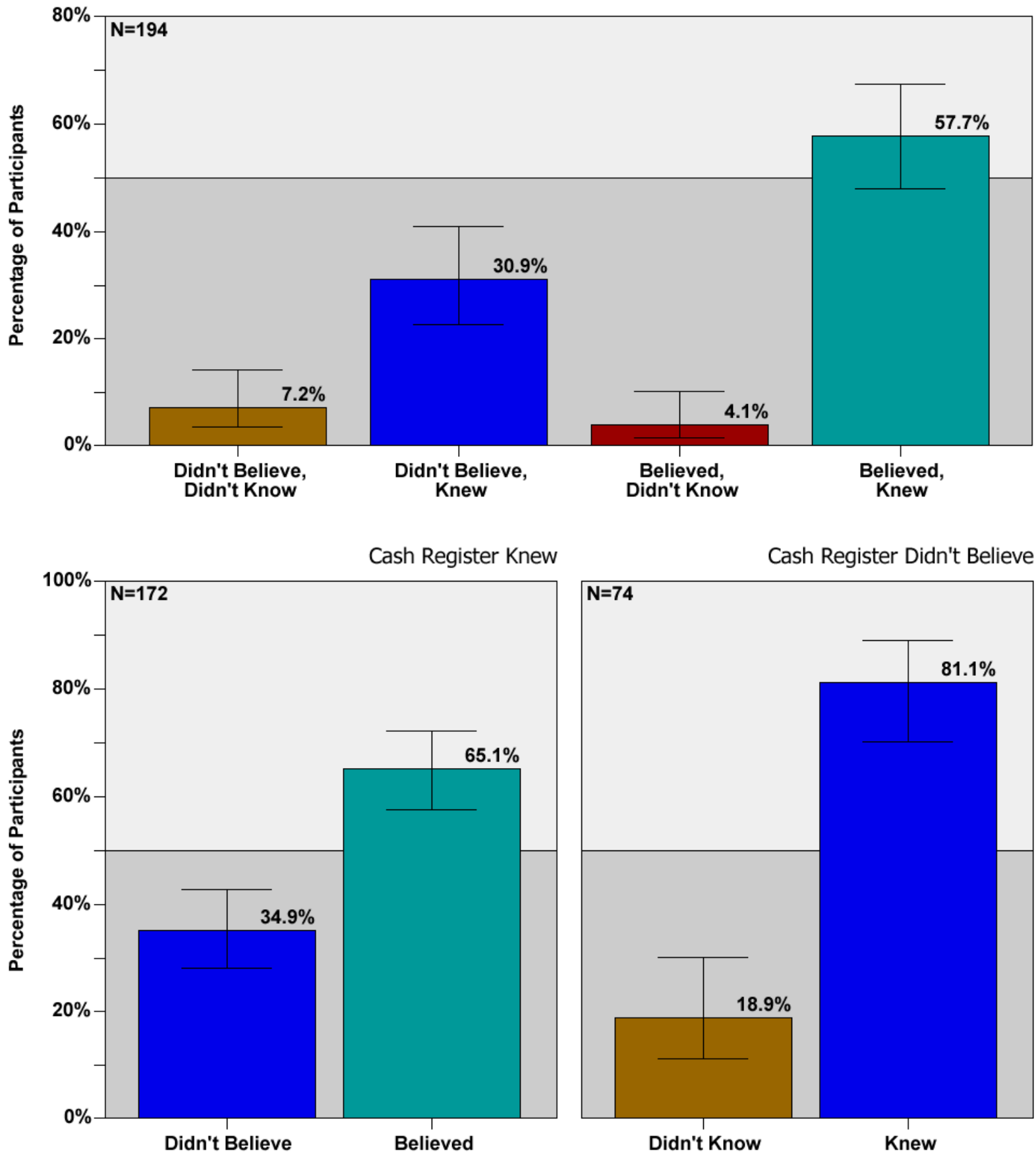

Fig. 3. Results of Study 3, with 95\% Confidence Intervals. All participants above; participants answering that the cash register knew bottom left; participants answering that it didn't believe bottom right.

\footnotetext{
${ }^{15}$ Restricting to the 92 participants who said they understood both questions literally, $32.4 \%$ answered that the cash register knew but did not believe $\left(\chi^{2}=6.39, \mathrm{df}=1, \mathrm{p}=0.006\right.$, one-tailed) and $63.2 \%$ answered that the cash register did not believe but nonetheless knew $\left(\chi^{2}=41.58, \mathrm{df}=1, \mathrm{p}<.001\right.$, one-tailed), both of which are significantly greater proportions than 0.2 .
} 


\subsection{Geocentrist}

In our fourth study, participants were given a vignette about a human being:

Karen is a first-year student at a prestigious university. She is a good student and has been doing very well in her classes. One of the classes she is taking is introduction to physics. One of the topics covered in this class is the place of the earth in the solar system. For example, one of the things that Karen has been taught is that the earth revolves around the sun.

Prior to starting at the university, however, Karen was home-schooled by her parents. Karen's parents taught her that the earth is at the center of the universe. Karen accepts what her parents have taught her. In particular, despite what she has been taught in her physics class, she holds that the earth does not revolve around the sun.

One of the questions on the final exam in Karen's physics class is the following:

True or false: The earth revolves around the sun.

Karen answers "true" on this question. She gets the question correct and ends up scoring $100 \%$ on the exam.

Each participant was then asked two yes/no questions (counterbalanced for order):

Does Karen know that the earth revolves around the sun?

Does Karen believe that the earth revolves around the sun?

On a second page, participants were then asked whether or not the earth revolves around the sun.

Here again, the advocate of the entailment thesis should make two predictions: (i)

participants who answer that Karen knows will answer that she believes; and, (ii) participants

who answer that Karen does not believe will answer that she does not know. Yet again,

neither prediction was born out by the data.

Responses were collected from 98 participants (removing ten who answered that the

earth does not revolve around the sun). Among the participants who answered that Karen

knows that the earth revolves around the sun, $84.9 \%$ answered that she does not believe as

much, which is significantly greater than the $20 \%$ noise threshold. ${ }^{16}$ Among those who

answered that Karen does not believe, $56.3 \%$ nonetheless answered that she knows. ${ }^{17}$ Results are shown in Figure 4.

${ }^{16}$ One-sample test of proportion with continuity correction, $\chi^{2}=135.52, \mathrm{df}=1, \mathrm{p}<.001 ; 95 \% \mathrm{CI}[0.72,0.93]$.

${ }^{17}$ One-sample test of proportion with continuity correction. $\chi^{2}=63.46, \mathrm{df}=1, \mathrm{p}<.001 ; 95 \% \mathrm{CI}[0.45,0.67]$. 

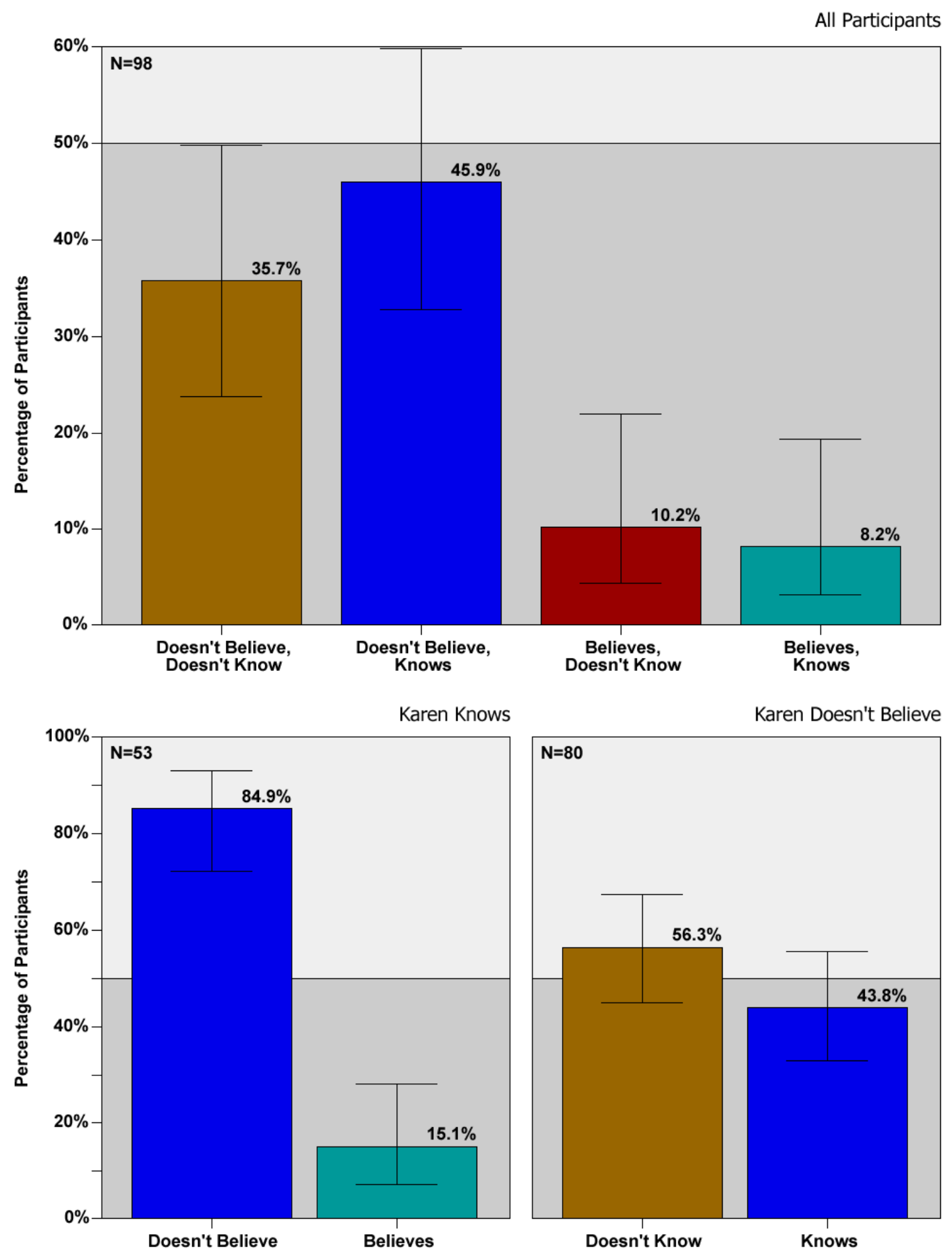

Fig. 4. Results of Study 4, with 95\% Confidence Intervals. All participants above; participants answering that Karen knows bottom left; participants answering that she doesn't believe bottom right. 


\section{Objections and Responses}

In four new studies, then, we find that a non-trivial minority of English speaking nonphilosophers ascribe knowledge but not belief to an agent. Indeed, in our fourth study, there are more people who answer that an agent believes but does not know than who give any other combination of knows and believes answers. Given these results, we hold that the entailment thesis should not be granted the default status that it is typically taken to have; rather, it stands in need of positive support. As we saw in Section 1, the most prominent attempts to provide such support — those of Lehrer (1968) and Armstrong (1969) —ultimately rest on contested intuitions themselves. Whether other arguments for the entailment thesis will meet with more success remains to be seen.

Given the diversity of our proposed counterexamples, we doubt that a compelling "one size fits all" objection to our interpretation of these results will be forthcoming. Nonetheless, a sequence of objections that jointly covered all four cases would cast doubt on our challenge to the default status of the entailment thesis. In this section we consider four such possible objections.

\subsection{The False Implicature Objection}

One might object that when participants in our studies denied that the agent believed the proposition, they were reading the question in terms of "mere belief." This objection could be based on either of two pragmatic considerations, the first of which poses more of a problem for our first study, the second for the last three (especially our final study).

The first way into the mere belief worry is the false implicature objection. Perhaps participants are sensitive to pragmatic considerations in a way that leads them to worry that answering "yes" to the believes question would be less than fully informative, leading their conversational partner - the experimenter - to infer that they did not think that they could 
truthfully make the more informative statement that the agent knew. These participants would then have answered "no" to the believes question not because they actually thought that God doesn't believe the proposition, but because they didn't want to imply that God doesn't know it. If this interpretation of the results of Study 1 is correct, then it fails to provide evidence against the default status of the entailment thesis.

The false implicature objection does not obviously apply to our last three studies, however. While our first study used a between-subjects design, such that participants receiving the belief question could not directly affirm that the agent knew the proposition, Studies 2-4 used a within-subjects design: Each participant received both the belief question and the knowledge question. Thus, each participant could directly affirm that the agent knew the proposition, which should remove the worry that a "yes" answer to the belief question would be taken to imply that the agent did not know the proposition.

To test whether the false implicature objection provides a correct interpretation for the results of our first study, we ran another, Study 5 . Given that the proposition that $2+2=4$ is not only epistemically trivial for God, but for most adult Americans, we used the same set-up as in Study 1, but replaced God with a well-known public figure. Participants were randomly assigned one of the following two yes/no questions:

Does Tom Hanks know that $2+2=4$ ?

Does Tom Hanks believe that $2+2=4$ ?

Since the pragmatic factors involved in the belief question seem to be the same for Tom Hanks as for God, if the infelicity objection is correct, we'd expect to find a similar gap between the percentages of "yes" answers for the two questions about Tom Hanks as we did for the corresponding questions about God in Study 1. But this is not what we found.

Responses were collected from 166 participants. Results are shown in Figure 5. There was no statistically significant difference between the "knows" and the "believes" conditions: $97.9 \%$ of participants answered that Tom Hanks knows that $2+2=4,93.0 \%$ that Hanks believes 
it. ${ }^{18}$ Thus, while participants in Study 1 were 27.2 percentage points more likely to answer that God knows that $2+2=4$ than that God believes it, this dropped to 4.9 percentage points for Tom Hanks. As such, the results of Study 5 tell against the false implicature objection.
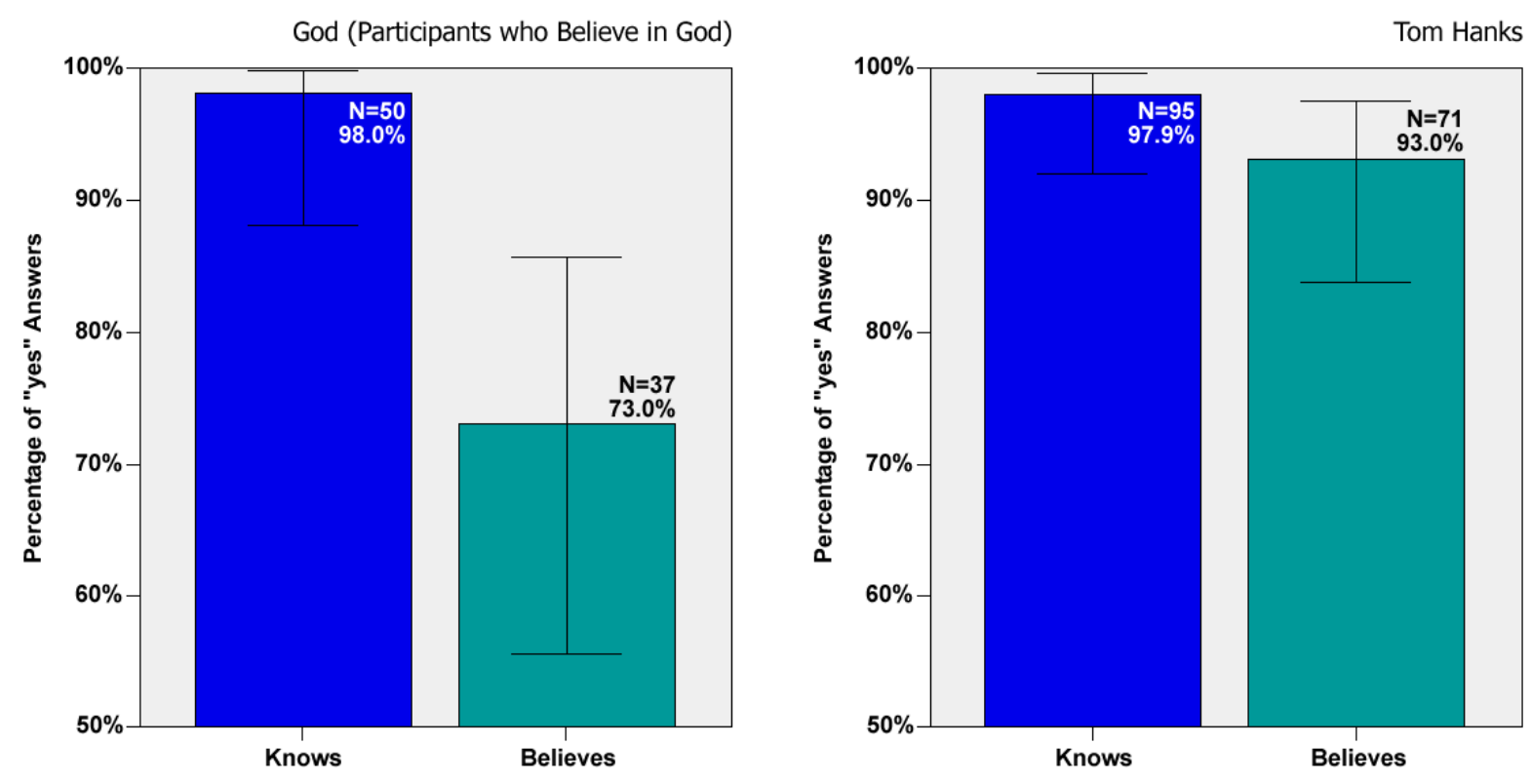

Fig. 5. Comparison of results for God (Study 1) to Tom Hanks (Study 5), with 95\% Confidence Intervals.

\subsection{The Redundancy Objection}

The worry that the belief questions in our studies were understood in terms of mere belief could fuel a second type of objection. The redundancy objection is similar to the false implicature objection, but grounded in a different type of pragmatic concern that more clearly applies to the within-subjects designs used in Studies 2-4. The false implicature objection argues that participants might be concerned that answering that the agent believes will be taken to imply that they do not think that the agent knows, and so does not arise when participants are asked both whether the agent knows and whether the agent believes.

Nonetheless, participants might have a related concern in these cases.

\footnotetext{
${ }^{18}$ With 166 participants, we had power of 0.8 to detect a medium-sized effect $(\mathrm{h}=0.44)$, and power of 0.97 to detect an effect as large as that seen in the God case $(\mathrm{h}=0.6)$. Two-sample test for equality of proportions with continuity correction, $\chi^{2}=1.38, \mathrm{df}=1, \mathrm{p}=0.24$.
} 
If participants take knowledge to entail belief, and take it to be common knowledge that the agents in our studies know the relevant propositions, then they should consider the belief question to be redundant given the knowledge question. The same would be true if they interpreted the belief question in terms of mere belief (taking mere belief to entail that the agent does not know), but not all redundancies are equally confusing, and participants might worry that responding that the agent both knows and believes is especially confusing. Doing so might, for example, be thought akin to reporting a roll of "an odd and a three" on a single die. Not only is such a report redundant, but redundant in a way that might suggest that the speaker is confused about what being an odd number amounts to. (In contrast, it doesn't sound nearly as strange to say that the number rolled "isn't even, it's a three.”) Similarly, participants in our studies might worry that saying that the agent both knows and believes would suggest that they are confused about the relationship between knowledge and belief, motivating them to look for an alternative reading to one of the questions. Reading the belief question in terms of mere belief would resolve this concern: Responding that the agent doesn't merely believe but knows sounds more natural and does not intimate any confusion.

While we don't find the redundancy objection as compelling as the false implicature objection, it is most plausible when participants are likely to think it obvious that the agent knows the proposition at issue. If a participant takes the knowledge question to be open to reasonable doubt, then the belief question is naturally read as giving them the opportunity to endorse a weaker position, so they shouldn't worry that saying that the agent both knows and believes will be taken to betray any confusion on their parts. As such, the redundancy objection seems to have the most traction with Study 4, since the human, Karen, is a more sophisticated cognitive agent than either the dog (Study 2) or cash register (Study 3). Even if a participant thinks that the dog knows that $2+2=4$ or that the cash register knows that the 
total is $\$ 42.73$, there seems to be ample room for reasonable doubt with regard to these claims given the types of agents involved.

In our sixth study, we tested the redundancy objection with respect to Study 4. To make the vignette a more obvious instance of belief, we altered the second paragraph: Whereas in Study 4 Karen continued to accept her parents' teaching that the sun revolves around the earth, in Study 6 she comes to accept that the earth revolves around the sun. ${ }^{19}$ Since the factors that underlie the redundancy objection are the same across Studies 4 and 6, if the objection is correct we would expect a similar proportion of the participants answering that Karen knows to deny that she believes. In fact, if the results of Study 4 are to be a guide, the redundancy objection predicts that considerably more than half of the participants who assert that Karen knows will deny that she believes.

Responses were collected from 66 participants. As seen in Figure 6, the results do not support the prediction made by the redundancy objection. Among the 51 participants who asserted that Karen knows that the earth revolves around the sun, only $10(19.6 \%)$ denied that Karen believes as much. Rather, 41 out of 51 (80.4\%) asserted that Karen believes. Hence, significantly less than half of the participants who said that Karen knows denied that she believes. ${ }^{20}$ Since the redundancy objection does not explain the pattern of results in Study 6, we reject it as an interpretation of Study 4. And since the objection was prima facie strongest for Study 4, these results also suggest that it's not the correct interpretation of Studies 2 or 3, either.

\footnotetext{
${ }^{19}$ The revised second paragraph reads: "Prior to starting at the university, however, Karen was home-schooled by her parents. Karen's parents taught her that the earth is at the center of the universe. Since starting at the university, though, Karen has quickly come to reject many of the things that her parents taught her. In particular, despite what her parents taught her, she now holds that the earth revolves around the sun."

${ }^{20}$ One-sample test of proportion with continuity correction, $\chi^{2}=17.65, \mathrm{df}=1, \mathrm{p}<0.001$. In fact, using our $20 \%$ noise threshold, the proportion who deny that Karen believes (among those who say that Karen knows) is not statistically different from noise $\left(\chi^{2}=0, \mathrm{df}=1, \mathrm{p}=1\right)$. The results of Study 6 also speak to the false implicature objection. If that objection held for Study 4, then the gap between "yes" answers to the knows and believes questions was due to participants' worry that the former would imply a negative answer to the latter (even though they were also explicitly asked the latter). If that were the case, then since the relevant pragmatic factors are the same, we should see a similar gap between "yes" answers to the knows and believes questions in Study 6. In fact, though, the proportion of participants in Study 6 who said that Karen believes (out of those who said that Karen knows) was significantly greater than the proportion of analogous participants in Study 4, and the effect size for this comparison is considerable $(\mathrm{h}=1.43)$. One-sample test of proportion with continuity correction, $\chi^{2}=41.89, \mathrm{df}=1, \mathrm{p}<0.001$.
} 

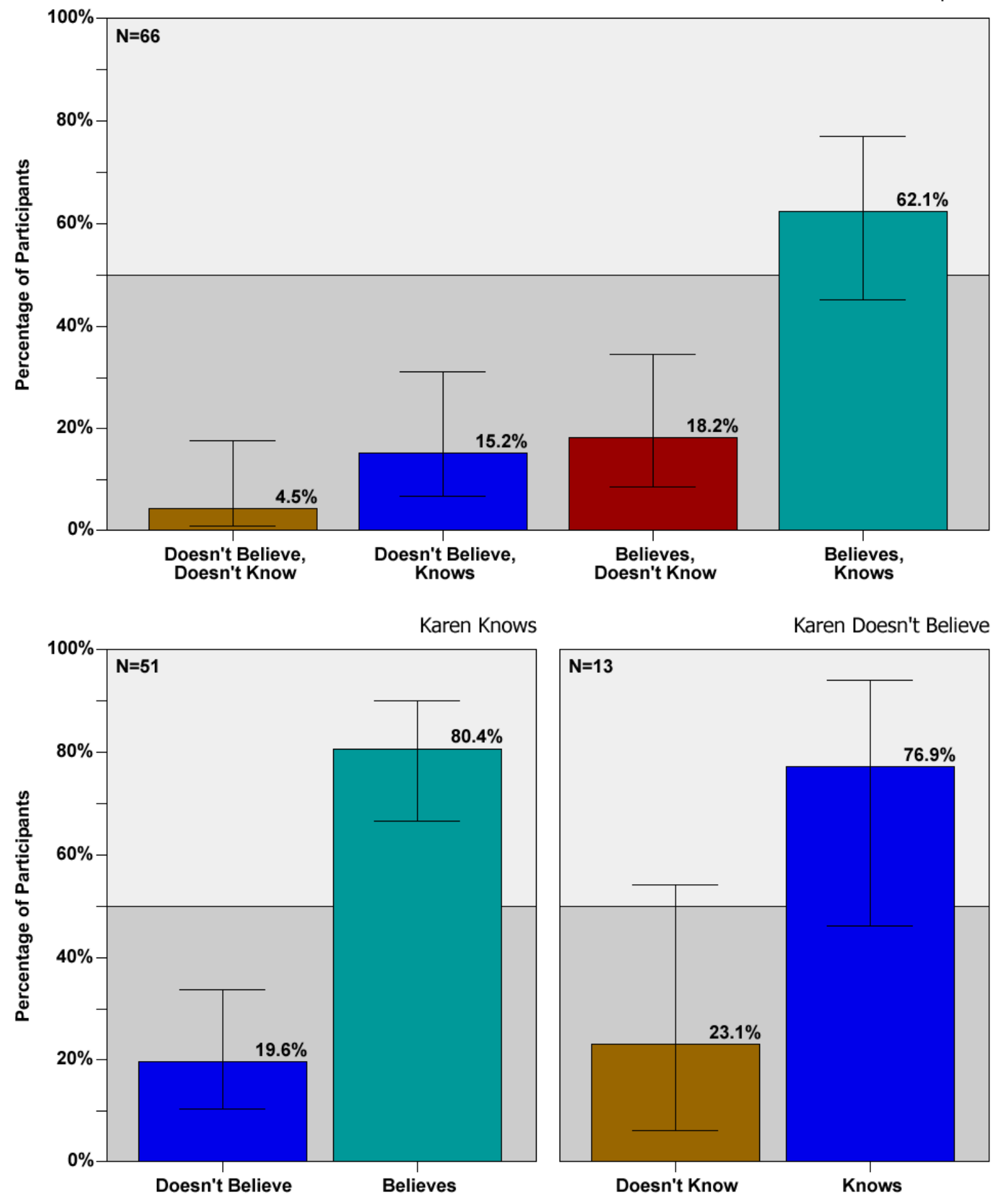

Fig. 6. Results of Study 6, with 95\% Confidence Intervals. All participants above; participants answering that Karen knows bottom left; participants answering that she doesn't believe bottom right. 


\subsection{The Know-how Objection}

The third objection to our interpretation of our studies presented in Section 3 is that participants who attributed knowledge to the agents did so because they interpreted the questions not to be asking about propositional knowledge, but about know-how. Since the entailment thesis is generally formulated in terms of propositional knowledge, our results would not then support the claim that a non-trivial minority took the cases to provide examples of propositional knowledge without belief.

We do not find this objection prima facie compelling. In each of our studies, the "knows" question was phrased in terms of propositional knowledge, as indicated by the word "that" (e.g., "Does God know that 2+2=4?"). As such, absent evidence to the contrary, we see no non-question-begging reason to suppose that participants interpreted these questions in terms of know-how. Further, insofar as the cash register is the least complex of the agents in our studies, the know-how objection would seem most plausible as applied to Study 3, but the evidence suggests against it in this case. Recall that we asked participants in this study on a second page whether they understood the knows and believes questions literally. More than half (60.5\%) answered "yes" to the knowledge question, and our results remain significant even after removing participants who answered "no" to whether they had understood either it or the belief question literally (see note 17). Insofar as the "that" recommends a literal reading in terms of propositional knowledge, this finding tells against the know-how interpretation. $^{21}$

\footnotetext{
${ }^{21}$ Wielding the know-how objection against our other studies also seems somewhat unsafe for other reasons. After all, any purported display of propositional knowledge could instead be construed as a display of knowhow-e.g., of knowing how to answer a corresponding question. For the advocate of the entailment thesis to generalize on the know-how objection in this way, however, would be to cut off her nose to spite her face: It would undermine any analysis of propositional knowledge by raising doubts about its very existence, not just an analysis of it according to which it entails belief. As such, for the know-how objection to be wielded safely, specific reasons are needed for thinking that it applies to any given case. But it is unclear, at best, what those reason(s) would be with respect to the more sophisticated agents in Study 1 (God) and Study 4 (Karen).
} 


\subsection{The Dispositional Belief Objection}

As noted in Section 2, Rose and Schaffer (ms) argue that the relevant sense of belief for the entailment thesis is dispositional, rather than occurrent. Further, they provide empirical evidence suggesting that participants in two of Myers-Schulz and Schwitzgebel's studies (the Unconfident Examinee and Freaked-Out Movie-Watcher) understood "belief" in the occurrent sense. When Rose and Schaffer prime participants to read the questions in these cases in terms of dispositional belief instead, they find that most give judgments consistent with the entailment thesis. This same line of objection might be raised against our studies.

Rose and Schaffer's objection to Myers-Schulz and Schwitzgebel's examples hinges on the information stored in agents' minds being in some way blocked from conscious access. In the Unconfident Examinee, for instance, Kate's mind goes blank when she is asked the question. Rose and Schaffer argue that Kate nonetheless has a dispositional belief about when Queen Elizabeth died - her panic about being out of time on the exam simply masks it. It does not seem, however, that there are any similar blocks involved in our four cases. The propositions involved in these studies are presumably easy for the agents to access and the wording of the vignettes does nothing to suggest such a block. In fact, the agents in Studies 3 and 4 readily exhibit their possession of the relevant information. Moreover, and importantly, the belief questions in Studies 1 and 2 simply cannot plausibly be interpreted in terms of occurrent belief: Participants were not asked about any particular occasions on which the agents exhibited possession of the relevant information - they were merely asked, e.g., "Does God believe that $2+2=4$ ?" Thus, Rose and Schaffer's objection seems implausible as applied to Studies 3 and 4, and cannot explain the results of Studies 1 and 2, which can only be read in terms of dispositional belief.

It is also worth noting that the dispositional belief objection, as stated, does not obviously explain the results of Myers-Schulz and Schwitzgebel's Unconfident Examinee 
case. Kate does not actually seem blocked from accessing the information that Queen Elizabeth died in 1603 since she correctly gives this answer to the question, thereby demonstrating that the information is, in some sense, available to her. Still, something does seem to be blocked in this case: Kate does not recall having learned the information. We might elaborate this in terms of Kate being blocked from consciously accessing the information that would serve to justify the occurrent belief that Queen Elizabeth died in 1603 . Rose and Schaffer's claim seems better interpreted, in other words, as holding that the Unconfident Examinee and Freaked-Out Movie-Watcher involve blockage of access to some information relevant to the belief in question, but not necessarily the information that would constitute the content of that belief.

This re-interpretation of Rose and Schaffer's objection raises a further question: Why should whether one has an occurrent belief depend on whether one has conscious access to information that justifies it? As discussed in the next section, one plausible answer is that belief requires mental assent, and that people typically have accessible reasons for what they assent to. If participants' intuitions accord with this hypothesis, that would explain why many in Myers-Schulz and Schwitzgebel's studies judged that Kate does not occurrently believe that Queen Elizabeth died in 1603 - Kate was blocked from accessing the information that would justify her assent to that proposition. If not for the block, however, Kate is disposed to assent to the proposition. And if participants were sensitive to this fact about Kate's dispositions, that would explain why many of them did ascribe the dispositional belief to Kate in Rose and Schaffer's studies. ${ }^{22}$

\footnotetext{
${ }^{22}$ It is worth noting that Rose and Schaffer's objection to Myers-Schulz and Schwitzgebel might be challenged even on the amendment above. One might think that the entailment thesis naturally concerns both dispositional and occurrent belief. For instance, one might maintain that the entailment thesis should hold both that (i) occurrent knowledge entails occurrent belief and (ii) dispositional knowledge entails dispositional belief. Suppose, then, that Rose and Schaffer are right that participants in Myers-Schulz and Schwitzgebel's studies did read the "believes" questions in terms of occurrent belief, but that participants in Rose and Schaffer's studies read them in terms of dispositional belief. In that case, if participants read the "knows" and "believes" questions in the same sense (i.e., if they read both in either the dispositional sense or both in the occurrent sense), then while Rose and Schaffer's results would show that the Unconfident Examinee and Freaked-Out Movie-Watcher
} 


\section{Capacities, Tendencies, and Assent}

Having moved past the objections to our studies considered in the previous section, we reaffirm our conclusion: Given the diversity of examples now on offer, the entailment thesis should not be granted the default status that it is typically taken to have. Myers-Schulz and Schwitzgebel note a further worry that could be raised at this point, however: Some might find it unappealing to reject the traditional account of knowledge - or a condition on it— without an alternative with which to replace it. We do not find this worry compelling. The lack of a clear replacement may indeed be unsettling, but that is hardly reason to embrace an unsupported claim. Although ignorance is unappealing, it is surely worse to ignore the evidence, and the evidence indicates that philosophers should no longer simply assume that the entailment thesis is true.

Nonetheless, we do think that it is worth exploring how the full set of results now on offer can best be explained. The alternative account of knowledge that Myers-Schulz and Schwitzgebel tentatively suggest to explain their results (the capacity-tendency account) does not seem to explain the results of our studies. Following Joseph Margolis (1973: 78), they suggest that knowledge involves "one's capacity to provide the right information in the right way," whereas belief involves "the likelihood that one would perform appropriately if one were asked to." Our dog, cash register, and geocentrist, however, all plausibly have both the capacity to provide the correct answer to the question at issue and exhibit the tendency to do so. ${ }^{23}$ The capacity-tendency account, then, would seem to wrongly predict that there would be no asymmetry in attributions of knowledge and belief in these studies.

do not present counterexamples to (ii), they would fail to show that Myers-Schulz and Schwitzgebel's results do not present counterexamples to (i). Of course, Rose and Schaffer argue that the entailment thesis only involves (ii). And, even if it were granted that the thesis also involves (i), their results would still show that Myers-Schulz and Schwitzgebel's studies do nothing to challenge (ii). As discussed in the text, our studies do.

${ }^{23}$ While God does not exhibit the tendency to provide the correct answer to the question at issue in our first study, it nonetheless seems plausible that God has the capacity to do so and would exhibit the tendency to do so if the situation arose. 


\subsection{The Conviction Account}

We are not prepared to fully endorse any alternative account of knowledge, nor any detailed account of belief, but we would like to tentatively suggest a different account that can explain the deviations from the entailment thesis seen in the full range of cases now on offer. Building off of our amendment to Rose and Schaffer's objection in the previous section, we suggest that the availability of information to the mind is not, intuitively, sufficient for belief. Rather, one must also have the right sort of attitude toward that information - namely, one must mentally assent to it. Call the assent condition on a type of propositional attitude the requirement that, to have such an attitude with proposition $p$ as its content, one must either (i) currently mentally assent to $p$, (ii) have mentally assented to $p$ in the past and not (yet) have disavowed $p$, or (iii) be currently disposed to assent to $p$. Any theory according to which there is an assent condition on belief, but not knowledge, falls under the umbrella of what we will call the conviction account. We suggest that all of the current empirical results on the entailment thesis can be explained by the hypothesis that participants who ascribe knowledge but not belief (implicitly) hold a conviction account. Specifically, we take clauses (ii) and (iii) to be intuitive conditions on dispositional belief, clause (i) on occurrent belief, and none of the clauses to be intuitive conditions on knowledge.

Different versions of the conviction account might spell out the type of assent required for belief in different ways. First, assent could be understood in terms of having a particular type of phenomenology — a subjective feeling of conviction in a proposition's truth. It seems plausible that part of what distinguishes belief from closely related types of propositional attitude, like supposition, in other words, is that it has a very different kind of phenomenal character. ${ }^{24}$ Alternatively, one might spell out assent in terms of believing a proposition on the basis of deliberation regarding its justification. Consider thoughts that

\footnotetext{
${ }^{24}$ Horgan and Tienson (2002) and Pitt (2004), e.g., argue that belief has a unique phenomenology.
} 
spontaneously pop into one's stream of consciousness, completely unbidden (e.g., "most of the birds I've ever seen are purple"). We hesitate to count such a thought as a belief since it is not arrived at on the basis of deliberation. More strongly, assent might be spelled out in terms of explicitly reflective deliberation. Thus, there seem to be cases involving thoughts similar to those involved in the example above that we could more readily offer reasons for, and yet in which we aren't aware of having arrived at those thoughts through conscious deliberation in light of those reasons. Imagine, for instance, that the thought "I should go to the store" occurs to you after you just had a craving for a bag of cashews. The thought seems reasons-sensitive in a sense (going to the store would fulfill one of your desires), but it also does not seem to be the result of consciously recognizing the desire and reasoning that a trip to the store would enable you to fulfill the desire Again, we feel somewhat hesitant to call this thought a belief, and find it plausible that our hesitation has its roots in an intuitive requirement that beliefs be formed on the basis of reflective deliberation concerning their justification.

Whether assent is elaborated in terms of phenomenology, deliberation, or some other factor, the conviction account bears a close affinity to assent theories of belief. The conviction account, however, has the advantage of being in less tension with functionalism. ${ }^{25}$ Historically, functionalist theories of belief supplanted assent theories, according to which the belief that $p$ consists in either mentally assenting to $p$ - having a conscious, occurrent thought that $p$ is the case - or else a disposition to such mental assent. ${ }^{26}$ In contrast, while functionalists accept that assent is one common manifestation of belief (along with further characteristic causal roles involving perceptual inputs, inferential connections to other mental states, and assertive and action-guiding outputs when appropriately related to desires), they typically deny that mental assent is either necessary or sufficient for belief.

\footnotetext{
${ }^{25}$ The conviction account is also similar to recent dispositional theories of belief that stress a wide range of causal roles and the importance of phenomenology, though some of these theories (e.g., Schwitzgebel 2002) retain the functionalist thesis that there is no specific phenomenal character that is necessary for belief (in contrast to at the least the phenomenological elaboration of the conviction account).

${ }^{26}$ See, e.g., Armstrong (1973: 3-7) and Price (1969).
} 
There are three key differences between assent theories of belief and the conviction account. First, assent theories are silent about whether assent is required for knowledge, whereas the conviction account explicitly denies that it is. Second, while the conviction account holds that assent is a necessary condition on belief, it does not hold that it is sufficient. Thus, while the conviction account emphasizes the role of mental assent, it does not deny that playing other functional roles may be necessary conditions on belief, as well. Third, unlike assent theories of belief, the conviction account allows that one could believe a proposition without either occurrently assenting to it or having the disposition to do so.

The latter two differences allow the conviction account to withstand the two primary lines of criticism that functionalists have leveled against assent theories. First, since the conviction account only holds that mental assent is necessary for belief, it is not subject to counterexamples involving "empty assent" (Price 1969: 19-21; Mellor 1978: 83). It has been argued that if one mentally assents to a proposition $p$, but does not manifest any of the other causal roles characteristic of believing that $p$, one does not believe that $p$. Unlike assent theories, the conviction account can agree that such cases of empty assent do not involve belief, since it denies that assent is a sufficient condition on belief..

Second, the conviction account escapes purported counterexamples involving unconscious belief. Price, for instance, asks us to consider an agent $A$ such that "all or most of the other manifestations of a belief that $p$ do occur in him, but he does not assent to the proposition $p$ when he entertains it and attends to it, and perhaps he even rejects it" (Price 1969: 299-300; see also Mellor 1978: 88-89). Price claims that this is a case of belief, despite the fact that agent $A$ lacks the disposition to assent to $p$. Whether or not Price's example is a case of belief, however, seems to depend on just how one fills in its details. One way of filling in the details of the case would correspond to Study 4: The geocentrist Karen acts as if 
she believes that the earth revolves around the sun, even though she rejects that proposition. ${ }^{27}$ This is not a case of belief according to the conviction account - unconscious or otherwisesince Karen does not meet any of conditions (i)-(iii).

Of course, the details of Price's example could be specified in a way that would make it more plausibly a case of unconscious belief. Consider, for example, Victoria, who at some point in the past mentally assented to a proposition corresponding with a racial stereotype.

Suppose that for some time afterwards Victoria acts in ways that are consistent with believing that proposition and does not reconsider her acceptance of it despite having seen a number of counterexamples to the stereotype. Suppose, though, that Victoria does come to reconsider the proposition at some later time, when she recalls the counterexamples she's seen and rejects the proposition. In such a case, there might be a period shortly prior to this reconsideration during which Victoria continued to act in ways that were consistent with believing the proposition, yet would no longer assent to it if she were explicitly asked about it, since she's come to a point where any such prompt would lead her to reconsider and then reject the proposition. Following Price, it could be argued that Victoria is not disposed to assent to the proposition during this period; and yet, based on her actions we might well want to say that she continues to believe it. ${ }^{28}$ Even granting this, however, the case still does not serve as a counterexample to the conviction account. According to clause (ii) of the assent condition, having mentally assented to a proposition in the past can be sufficient for one to count as believing that proposition at a later time - even if one does not assent to that proposition at that time and lacks the disposition to do so. Price's example could, of course,

\footnotetext{
${ }^{27}$ It might be argued that Karen does not display "all or most" of the behaviors that we would associate with belief in the vignette as written. Such details could be added without significant alteration, however.

${ }^{28}$ Alternatively, Victoria may still be disposed to assent during this period until she is explicitly asked about the proposition because such a prompt changes her disposition by leading her to reflect. This is consistent with the conviction account, and would render condition (ii) superfluous. Nonetheless, for purposes of the objection we will assume that this example is a case of belief without the disposition to assent. We thank an anonymous referee for Philosophical Studies for bringing this point to our attention.
} 
be spelled out in yet other ways, but we doubt that the details can be filled in to provide a clear case of belief that the conviction account fails to classify as a belief.

\subsection{Explaining the Results}

The conviction account appears to explain all of the current experimental results. First, if people take belief, but not knowledge, to require mental assent, that would explain why most participants were more likely to ascribe knowledge than belief to all of the agents in our four studies. While the dog, cash register, and geocentrist have learned true propositions and are able to provide them when prompted, it is reasonable to doubt whether any of them has mentally assented to those propositions: The geocentrist explicitly rejects the proposition, and the cash register and dog plausibly lack the capacity to mentally assent altogether. In Study 1, people may hesitate to ascribe belief to God either because God lacks the requisite phenomenology (see Gray, Gray, and Wegner, 2007), or because they doubt that God would ever engage in the type of deliberation required for mental assent about the proposition that $2+2=4$.

Second, following the suggestion in Section 4.4, the conviction account can explain why participants attributed dispositional beliefs to the agents in the Unconfident Examinee and Freaked-Out Movie-Watcher in Rose and Schaffer's studies, while participants in MyersSchulz and Schwitzgebel's studies did not ascribe occurrent beliefs to either. In the Unconfident Examinee, Kate does not satisfy clause (i) of the assent condition-she does not assent to the proposition that Queen Elizabeth died in 1603 at the time of the exam (she thinks she is guessing) — and so does not have the occurrent belief that this was when Elizabeth died. Kate does, however, meet clauses (ii) and (iii) of the assent condition: She previously assented to the proposition in question, has not since disavowed it, and would do so again if not for the disposition being blocked by her panic. Thus, Kate meets the conviction account's conditions for having the dispositional belief that Queen Elizabeth died 
in 1603. Similarly, Jamie in the Freaked-Out Movie-Watcher is plausibly disposed to assent to the proposition that only water (and not aliens) will come out of the faucet, even though at the time in question her fear masks this disposition from leading to its normal behavioral consequences and any occurrent mental assent. Thus, Jamie meets clause (iii), but not (i), of the assent condition, so the conviction account correctly predicts that participants ascribe dispositional but not occurrent belief to her.

Perhaps the most difficult case for the conviction account to explain is Myers-Schulz and Schwitzgebel's Prejudiced Professor. Juliet openly affirms that her student athletes are just as academically capable as her non-athlete students - suggesting mental assent - but she treats them otherwise. In response to this scenario, most participants judged that Juliet knows that her athletic students are as capable as her other students, but they hold that she does not believe as much. While further work is needed on this case for several reasons - not least of which is the difficulty raised by Rose and Schaffer concerning the potentially biasing nature of its moral valence — we find it plausible that given the professor's behavior, participants may take her affirmation to lack sincerity. For example, the vignette reports that when an athlete "writes the best essay in the course... Juliet is surprised," suggesting that she is not truly convinced of the academic equality of athletes and non-athletes. Thus, while Juliet pays lip-service to equality, other aspects of the vignette indicate that she does not truly assent to the proposition at issue.

Overall, then, we find that the conviction account is better able to explain the current range of results than Myers-Schulz and Schwitzgebel's capacity-tendency account, although this may change as further studies on the entailment thesis amass. Regardless of how best to explain the phenomenon, our evidence suggests that it is robust: Across a wide variety of cases, a non-trivial percentage of English speakers ascribe propositional knowledge to an agent without the corresponding belief. As such, the evidence indicates that the entailment 
thesis does not deserve the default status that it's been allowed it to enjoy. Epistemologists cannot simply assume that the entailment thesis is true on the basis of intuition; instead, it must be given positive support. 


\section{References}

Armstrong, D. 1969. Does Knowledge Entail Belief? Proceedings of the Aristotelian Society 70: 21-36.

Armstrong, D. 1973. Belief, Truth, and Knowledge. Cambridge: Cambridge University Press.

Black, C. 1971. Knowledge without Belief. Analysis 31: 152-58.

Cohen, J. 1966. More about Knowing and Feeling Sure. Analysis 27: 11-16.

Horgan, T., and Tienson, J. 2002. The Intentionality of Phenomenology and the Phenomenology of Intentionality. In D. Chalmers (ed.), Philosophy of Mind: Classical and Contemporary Readings.

Oxford: Oxford University Press, 520-33.

Johnston, M. 1992. How to Speak of the Colors. Philosophical Studies 68: 221-263.

Jones, O.R. 1971. Knowing and Guessing: By Examples. Analysis 32: 19-23.

Lehrer, K. 1968. Belief and Knowledge. The Philosophical Review 77(4): 491-499.

Lehrer, K. 1990. Theory of Knowledge. Boulder, CO: Westview Press.

Lewis, D. 1996. Elusive Knowledge. Australasian Journal of Philosophy 74: 549-67.

Mannison, D. S. 1976. "Inexplicable Knowledge" does not Require Belief. Philosophical Quarterly 26: $139-48$.

Margolis, J. 1973. Knowledge and Existence. New York: Oxford University Press.

Mellor, D. H. 1978. Conscious Belief. Proceedings of the Aristotelian Society 78: 87-101.

Myers-Schulz, B., \& Schwitzgebel, E. Forthcoming. Knowing That P without Believing That P. Noûs.

Naess, A. 1938. “Truth” As Conceived By Those Who Are Not Professional Philosophers. Oslo: I

Kommisjon Hos Jacob Dybward.

Pitt, D. 2004. The Phenomenology of Cognition, or, What Is It Like to Think That P? Philosophy and Phenomenological Research 69: 1-36.

Price, H. H. 1969. Belief. London: George Allen \& Unwin.

Radford, C. 1966. Knowledge—By Examples. Analysis 27(1): 1-11.

Rose, D., \& J. Schaffer (ms). "Knowledge Entails Dispositional Belief."

http://www.jonathanschaffer.org/knowbelieve.pdf

Schope, R. 2002. Conditions and Analyses of Knowing. In P. Moser (ed.), The Oxford Handbook of Epistemology. New York: Oxford University Press.

Schwitzgebel, E. 2002. “A Phenomenal, Dispositional Account of Belief.” Noûs 36: 249-75.

Sorensen, R. 1982. Knowing, Believing, and Guessing. Analysis 42: 212-13.

Sytsma, J. 2010. The Proper Province of Philosophy: Conceptual Analysis and Empirical Investigation. Review of Philosophy and Psychology 1(3): 427-445. 